\title{
Adsorption of alkali metal cations and halide anions on metal oxides: prediction of Hofmeister series using 1-pK triple layer model
}

\author{
Wojciech Piasecki • Piotr Zarzycki • Robert Charmas
}

Received: 5 March 2010 / Accepted: 14 June 2010 / Published online: 10 July 2010

(C) The Author(s) 2010. This article is published with open access at Springerlink.com

\begin{abstract}
Adsorption of electrolyte ions on metal oxides significantly affects the interfacial charge distribution. The general procedure for the prediction of surface charge on oxides in salt solutions was given by Sverjensky for the 2-pK Triple Layer Model (2-pK TLM) (Sverjensky, Geochim. Cosmochim. Acta 69:225-257, 2005). Based on his parameters values and by assuming parameters transferability (Piasecki, J. Colloid Interface Sci. 302:389-395, 2006) we have predicted the adsorption constants for three monovalent ions $\left(\mathrm{Rb}^{+}, \mathrm{F}^{-}, \mathrm{Br}^{-}\right)$for eight oxides within the framework of the 1-pK Triple Layer Model (1-pK TLM). The obtained parameters values along with the previously reported ones (Piasecki, J. Colloid Interface Sci. 302:389-395, 2006) allowed us to compare the adsorption affinities of alkali metal cations and halide anions, and construct the following Hofmeister series for the cations $\left(\mathrm{Cs}^{+} \approx \mathrm{Rb}^{+} \approx \mathrm{K}^{+}<\right.$ $\left.\mathrm{Na}^{+}<\mathrm{Li}^{+}\right)$and for the anions $\left(\mathrm{F}^{-} \gg \mathrm{Cl}^{-} \approx \mathrm{Br}^{-}<\mathrm{I}^{-}\right)$ for investigated oxides. The same lyotropic series was predicted by the 2-pK TLM. It indicates that Hofmeister series is invariable during parameter transfer between surface complexation models.
\end{abstract}

\footnotetext{
W. Piasecki ( $\square)$

Department of Biochemistry, Faculty of Physical Education in Biala Podlaska, The Josef Pilsudski University of Physical Education in Warsaw, 2 Akademicka Street, 21-500 Biala Podlaska, Poland

e-mail: wojciech.piasecki@awf-bp.edu.pl

P. Zarzycki

Chemical and Materials Sciences Division, Pacific Northwest

National Laboratory, Richland, WA, USA

R. Charmas

The State College of Computer Science and Business

Administration, Łomża, Poland
}

Keywords Hofmeister series · Ion adsorption · Metal oxides $\cdot 1$-pK model

\section{Introduction}

Metal (hydr)oxides, silica and water are the major components of the Earth's crust. The oxide/aqueous solution interface is crucial for many geochemical processes like the mineral weathering or the transport of elements in the environment (Stumm and Morgan 1996). In order to understand these important environmental phenomena one should realize that the adsorption of ions onto mineral surface is a key step. Due to ion adsorption and ionization of reactive surface groups the oxides gain a surface charge, whose sign and magnitude depends mainly on bulk $\mathrm{pH}$, although the type and concentration of electrolyte ions plays also a significant role (Davis and Kent 1990). In order to ensure constant ionic strength of investigated solution in laboratory experiments one often uses simple electrolyte (1:1 salts like $\mathrm{NaCl}$ or $\mathrm{KNO}_{3}$ ). In principle, this electrolyte should be indifferent, so that experimental results do not depend on the salt type. However in practice, the influence of electrolyte on experimental data was frequently reported (Kosmulski 2002).

To correctly describe the charge formation on oxide surface being in contact with the electrolyte solution the surface complexation model (SCM) was developed (Yates et al. 1974; Davis et al. 1978). In SCM we typically define a few surface reactions responsible for the surface charging. Additionally, we assume that charge distribution across the interface can be conceptually replaced by the set of layers. Finally, we get the model like 2-pK Triple Layer Model (2-pK TLM). 
In order to generalize the results obtained for various oxides in different salt solutions and predict the behaviour of the systems which had not been investigated so far, Sverjensky developed a predictive model of oxide surface charging based on crystal chemical and Born solvation theory (Sverjensky 2005). In this model the logarithms of equilibrium constants for surface reactions depend linearly on the reciprocal of the solid dielectric constant (solvation contribution) and the Pauling bond strength per angstrom (electrostatic contribution) (Sverjensky 1994). The coefficient values in these linear free energy relationship (LFER) equations can be determined by analyzing many sets of potentiometric titration data obtained for the different oxides in various electrolytes (this is model calibration step). As a final result Sverjensky obtained the set of equations from which he could calculate the thermodynamic parameters for a given oxide/electrolyte system even if the system had never been studied experimentally.

Sverjensky's model was based on earlier works of James and Healy (energy of solvation) (James and Healy 1972) and Yoon et al. (electrostatic interactions) (Yoon et al. 1979). Its recent, revised version from 2005 which is used in this paper evolved from original papers published in the 90s (Sverjensky 1994; Sverjensky and Sahai 1996; Sahai and Sverjensky 1997b, 1997a). In the last version the new method for prediction of e.d.l. capacitance was included and a new definition of standard state was systematically applied.

Surface complexation models (1-pK, 2-pK, MUSIC) differ about surface protonation mechanism but all assume binding of electrolyte ions at oxide surface. The values of protonation constants are constrained by some relations (e.g. dependence on PZC) or even can be determined a priori (MUSIC) (Hiemstra and van Riemsdijk 1991; Hiemstra et al. 1996). Adsorption constants of electrolyte ions are treated as freely adjustable parameters. For the given oxide/electrolyte solution system we obtain different values of electrolyte ions adsorption constants predicted by various models. Let's assume for example that one model predicts that sodium ions adsorbs onto given oxide slightly stronger than potassium ions. The question is if we obtain the same sequence applying another SCM? To check this we have chosen two models (2-pK and 1-pK) and used the parameter database for 2-pK TLM developed by Sverjensky (2005).

In our earlier paper we have transfered the parameters values obtained for the 2-pK TLM to the simpler 1-pK Triple Layer Model (1-pK TLM) (Piasecki 2006). It is worth mentioning that so far we have transferred the parameters for a limited range of oxides and electrolytes solutions chosen from the original paper (Sverjensky 2005). We chose 8 oxides $\left(\mathrm{Fe}_{3} \mathrm{O}_{4}, \alpha-\mathrm{MnO}_{2}, \alpha-\mathrm{TiO}_{2}, \beta-\mathrm{TiO}_{2}, \mathrm{Fe}_{2} \mathrm{O}_{3}\right.$, $\left.\alpha-\mathrm{Al}_{2} \mathrm{O}_{3}, \gamma-\mathrm{Al}_{2} \mathrm{O}_{3}, \mathrm{Al}(\mathrm{OH})_{3}\right)$, and 4 cations and 4 anions: $\mathrm{Li}^{+}, \mathrm{Na}^{+}, \mathrm{K}^{+}, \mathrm{Cs}^{+}, \mathrm{Cl}^{-}, \mathrm{I}^{-}, \mathrm{NO}_{3}^{-}, \mathrm{ClO}_{4}^{-}$(there were 4 salts: $\mathrm{LiNO}_{3}, \mathrm{NaCl}, \mathrm{KI}, \mathrm{CsClO}_{4}$ ) for which parameter values were predicted by Sverjensky. In fact we could also choose different salts interchanging the cations and the anions (e.g. $\mathrm{LiCl}, \mathrm{NaClO}_{4}, \mathrm{KNO}_{3}$, CsI). Such interchange of ions does not influence on the determined parameter values for the 1-pK TLM.

In the current study we would like to transfer the parameter values for three additional ions: rubidium, fluoride and bromide $\left(\mathrm{Rb}^{+}, \mathrm{F}^{-}, \mathrm{Br}^{-}\right)$. We need these ions to compare the adsorption affinities of the alkali metal cations $\left(\mathrm{Li}^{+}, \mathrm{Na}^{+}\right.$, $\left.\mathrm{K}^{+}, \mathrm{Rb}^{+}, \mathrm{Cs}^{+}\right)$and halide anions $\left(\mathrm{F}^{-}, \mathrm{Cl}^{-}, \mathrm{Br}^{-}, \mathrm{I}^{-}\right)$for different oxides.

The adsorption constants of simple ions are closely related with the popular in colloid science Hofmeister series (lyotropic series) (Lyklema 2009). "Hofmeister series ranks the relative influence of ions on the physical behavior of wide variety of aqueous processes ranging from colloid assembly to protein folding" (Zhang and Cremer 2006). In this paper we would like to determine the Hofmeister series for alkali metal cations and halide anions for various metal oxides by using the 1-pK TLM and check whether the parameter transfer from 2-pK TLM to 1-pK TLM can change the Hofmeister series.

\section{Theory}

In Fig. 1 we present a schematic diagram of the oxide/electrolyte solution interface according to the 2-pK and 1-pK Triple Layer Models.

In the 2-pK TLM the following surface reactions occur at metal oxide/electrolyte solution interface:

$$
\begin{aligned}
& \mathrm{SOH}+\mathrm{H}^{+} \stackrel{K_{1}}{\longleftrightarrow} \mathrm{SOH}_{2}^{+}, \quad K_{1}=\frac{\theta_{+}}{a_{H} \theta_{0}} \cdot \exp \left\{\frac{e \psi_{0}}{k T}\right\} \\
& \mathrm{SO}^{-}+\mathrm{H}^{+} \stackrel{K_{2}}{\longleftrightarrow} \mathrm{SOH}, \quad K_{2}=\frac{\theta_{0}}{a_{H} \theta_{-}} \cdot \exp \left\{\frac{e \psi_{0}}{k T}\right\} \\
& \mathrm{SO}^{-}+\mathrm{C}^{+} \stackrel{K_{2 \mathrm{C}}}{\longleftrightarrow} \mathrm{SO}^{-} \mathrm{C}^{+} \\
& K_{2 \mathrm{C}}=\frac{\theta_{\mathrm{C}}}{a_{\mathrm{C}} \theta_{-}} \cdot \exp \left\{\frac{e \psi_{\beta}}{k T}\right\} \\
& \mathrm{SOH}_{2}^{+}+\mathrm{A}^{-} \stackrel{K_{2 \mathrm{~A}}}{\longleftrightarrow} \mathrm{SOH}_{2}^{+} \mathrm{A}^{-} \\
& K_{2 \mathrm{~A}}=\frac{\theta_{\mathrm{A}}}{a_{\mathrm{A}} \theta_{+}} \cdot \exp \left\{-\frac{e \psi_{\beta}}{k T}\right\}
\end{aligned}
$$

The first two equations (1a), (1b) describe a proton association and dissociation on surface hydroxyl group $\mathrm{SOH}$, and the last two (1c), (1d) describe electrolyte ions binding to the surface. The appropriate equilibrium constant is assigned to each reaction.

In the case of the 1-pK Triple Layer Model (1-pK TLM) we distinguish only one surface reaction responsible for the 

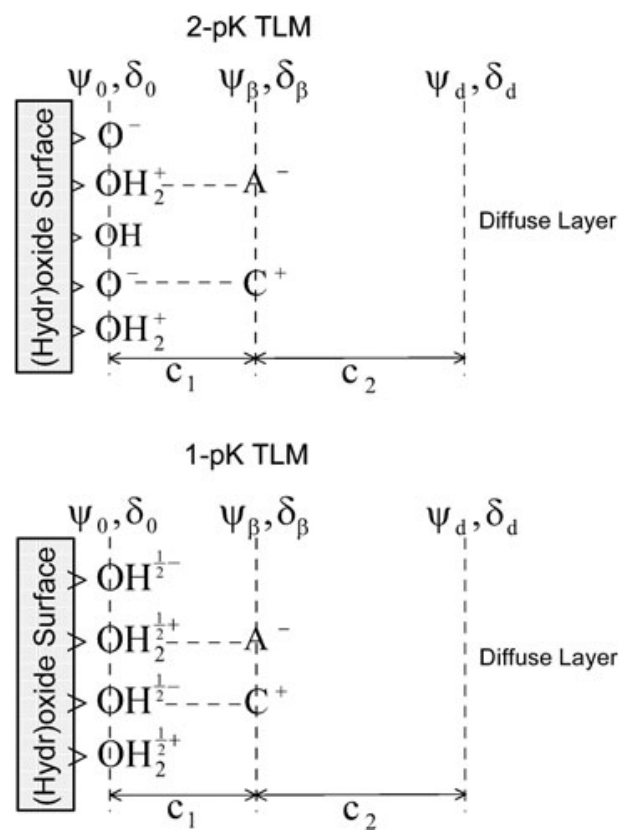

Fig. 1 Schematic diagram of the Triple Layer Model (TLM) structure with the surface species for the 2-pK and the 1-pK protonation approach. In the figure three planes can be distinguished: the surface plane $(0)$, the plane of adsorbed electrolyte ions $(\beta)$, and the plane being onset of diffuse layer $(d) . \psi$ denotes electric potential and $\delta$ charge located in individual planes. $c_{1}$ stands for the inner-layer capacitance and $c_{2}$ is the outer-layer capacitance. In this paper we assume that electrokinetic potential $\zeta$ corresponds to potential $\psi_{d}$

proton binding,

$$
\begin{gathered}
\mathrm{SOH}^{\frac{1}{2}-}+\mathrm{H}^{+} \stackrel{K_{+}}{\longleftrightarrow} \mathrm{SOH}_{2}^{\frac{1}{2}+} \\
K_{+}=\frac{\theta_{+}}{a_{\mathrm{H}} \theta_{-}} \cdot \exp \left\{\frac{e \psi_{0}}{k T}\right\} \\
\mathrm{SOH}^{\frac{1}{2}-}+\mathrm{C}^{+} \stackrel{K_{1 \mathrm{C}}}{\longleftrightarrow} \mathrm{SOH}^{\frac{1}{2}-} C^{+} \\
K_{1 \mathrm{C}}=\frac{\theta_{\mathrm{C}}}{a_{\mathrm{C}} \theta_{-}} \cdot \exp \left\{\frac{e \psi_{\beta}}{k T}\right\} \\
\mathrm{SOH}_{2}^{\frac{1}{2}+}+\mathrm{A}^{-} \stackrel{K_{1 \mathrm{~A}}}{\longleftrightarrow} \mathrm{SOH} \mathrm{SO}_{2}^{\frac{1}{2}+} \mathrm{A}^{-} \\
K_{1 \mathrm{~A}}=\frac{\theta_{\mathrm{A}}}{a_{\mathrm{A}} \theta_{+}} \cdot \exp \left\{-\frac{e \psi_{\beta}}{k T}\right\}
\end{gathered}
$$

In the above equations $\psi_{0}$ denotes the surface potential; $\psi_{\beta}$ is the mean potential at the plane where electrolyte ions are located; $a_{\mathrm{H}}, a_{\mathrm{C}}$, and $a_{\mathrm{A}}$ are the bulk activities of protons, and electrolyte cations and anions, respectively. The surface concentration of adsorption complexes is expressed by using the surface coverages: $\theta_{0}, \theta_{+}, \theta_{\mathrm{C}}, \theta_{\mathrm{A}}$. Exponential factors in (1), (2) account for the presence of electrical field at the interface. The ion concentration profile in electric field is given by Boltzmann distribution $a_{x}=a_{\text {bulk }} \exp \left\{-\frac{z e \psi_{x}}{k T}\right\}$, where $z$ is an ion charge.
Additionally, in the Triple Layer Model the distribution of electric charge at the interface is approximated by two capacitors connected in series, so one can express the relation between the charges and the potentials within the interface as (see Fig. 1),

$c_{1}=\frac{\delta_{0}}{\psi_{0}-\psi_{\beta}} \quad$ and $\quad c_{2}=\frac{-\delta_{d}}{\psi_{\beta}-\psi_{d}}$

where $c_{1}$ and $c_{2}$ denote the inner-layer and outer-layer capacitance, respectively.

The equations for the 2-pK TLM or the 1-pK TLM can be solved numerically for assumed values of the equilibrium constants and capacitances defined in (1)-(3). We can calculate surface coverages of the adsorbed species, as well as the surface charge and potential as a function of $\mathrm{pH}$. Finally, we can compare the model predictions with the experimental data or with the another model estimations.

\section{Results and discussion}

The 1-pK model is the simplest approach describing the surface charging of oxides in aqueous solutions however it sometimes gives unsatisfactory results. In the case of silica or quartz the protonation mechanism of the oxides can not be properly describe by the 1-pK model because the reaction responsible for surface charging of these oxides is the dissociation of protons from silanol groups $(>\mathrm{SiOH} \rightarrow$ $\left.>\mathrm{SiO}^{-}+\mathrm{H}^{+}\right)($Hiemstra and van Riemsdijk 1991). Therefore the 2-pK model gives much better description of silicon oxide charging than the 1-pK model. But even applying the 2-pK model it is hard to precisely determine equilibrium constant of electrolyte anion adsorption because charging curve of silica can practically be measured for $\mathrm{pH}>\mathrm{PZC}$, where anions are weakly adsorbed. So, we have decided to exclude silica and quartz from our study. This drawback is the price for the application of the 1-pK model-the simplest and general protonation mechanism available for metal oxides.

In this place it must be stressed that there are no problems in analyzing of silicon oxide charging by using Sverjensky's approach (where the 2-pK protonation mechanism was assumed). Additionally, this approach explains the anomalous position of silica on the surface acidity versus aqueous acidity correlation observed for metal oxides (Sahai 2002).

In order to increase the credibility of our results Sverjensky's method of predicting the oxide surface charge should be experimentally validated for the systems which have not been studied yet. However, we have not heard that somebody has published a paper which could considerably challenge Sverjensky's results. The parameter values obtained by him can not be treated as "final and true" - this is an approximation which is based on reliable thermodynamic framework. 
Table 1 Parameters values used in calculations for different oxides and $\mathrm{RbBr}$ solution. Parameters for the 2-pK TLM was taken from Sverjensky (2005). Parameters for the 1-pK model was determined in this study $\left(\log K_{1 \mathrm{C}}, \log K_{1 \mathrm{~A}}\right)$
Table 2 Parameters values used in calculations for different oxides and $\mathrm{NaF}$ solution. Parameters for the 2-pK TLM was taken from Sverjensky (2005). Parameters for the 1-pK model was determined in this study $\left(\log K_{1 \mathrm{~A}}\right)$

\begin{tabular}{llllllllr}
\hline Oxide & PZC & $\log K_{1}$ & $\log K_{2}$ & $c_{1}$ & $\log K_{2 \mathrm{C}}$ & $\log K_{2 \mathrm{~A}}$ & $\log K_{1 \mathrm{C}}$ & $\log K_{1 \mathrm{~A}}$ \\
\hline $\mathrm{Fe}_{3} \mathrm{O}_{4}$ & 7.4 & 4.6 & 10.3 & 1.03 & 3.1 & 2.8 & $\mathbf{0 . 5}$ & $\mathbf{0 . 3}$ \\
$\alpha-\mathrm{MnO}_{2}$ & 5 & 1.8 & 8.2 & 1.03 & 2.7 & 2.8 & $-\mathbf{0 . 1}$ & $\mathbf{0 . 0}$ \\
$\alpha-\mathrm{TiO}_{2}$ & 5.4 & 2.3 & 8.6 & 1.03 & 2.7 & 2.8 & $-\mathbf{0 . 1}$ & $\mathbf{0 . 0}$ \\
$\beta-\mathrm{TiO}_{2}$ & 6 & 2.8 & 9.2 & 1.03 & 2.6 & 2.4 & $-\mathbf{0 . 2}$ & $-\mathbf{0 . 4}$ \\
$\mathrm{Fe}_{2} \mathrm{O}_{3}$ & 9.5 & 6.8 & 12.3 & 0.90 & 2.7 & 2.1 & $\mathbf{0 . 2}$ & $-\mathbf{0 . 3}$ \\
$\alpha-\mathrm{Al}_{2} \mathrm{O}_{3}$ & 9.4 & 6.6 & 12.2 & 1.07 & 2.9 & 2.7 & $\mathbf{0 . 4}$ & $\mathbf{0 . 3}$ \\
$\gamma-\mathrm{Al}_{2} \mathrm{O}_{3}$ & 8.6 & 5.6 & 11.5 & 1.07 & 2.9 & 2.7 & $\mathbf{0 . 3}$ & $\mathbf{0 . 1}$ \\
$\mathrm{Al}(\mathrm{OH})_{3}$ & 9.8 & 7 & 12.6 & 0.65 & 2.8 & 2.5 & $\mathbf{0 . 3}$ & $\mathbf{0 . 1}$ \\
\hline
\end{tabular}

\begin{tabular}{lllllllll}
\hline Oxide & PZC & $\log K_{1}$ & $\log K_{2}$ & $c_{1}$ & $\log K_{2 \mathrm{C}}$ & $\log K_{2 \mathrm{~A}}$ & $\log K_{1 \mathrm{C}}$ & $\log K_{1 \mathrm{~A}}$ \\
\hline $\mathrm{Fe}_{3} \mathrm{O}_{4}$ & 7.4 & 4.6 & 10.3 & 1.31 & 3.4 & 5.0 & $\mathbf{0 . 8 5}$ & $\mathbf{2 . 4 5}$ \\
$\alpha-\mathrm{MnO}_{2}$ & 5 & 1.8 & 8.2 & 1.31 & 2.8 & 5.0 & $-\mathbf{0 . 0 5}$ & $\mathbf{2 . 1}$ \\
$\alpha-\mathrm{TiO}_{2}$ & 5.4 & 2.3 & 8.6 & 1.31 & 2.8 & 4.9 & $-\mathbf{0 . 0 5}$ & $\mathbf{2 . 1}$ \\
$\beta-\mathrm{TiO}_{2}$ & 6 & 2.8 & 9.2 & 1.31 & 2.5 & 4.3 & $-\mathbf{0 . 3}$ & $\mathbf{1 . 4}$ \\
$\mathrm{Fe}_{2} \mathrm{O}_{3}^{b}$ & 9.5 & 6.8 & 12.3 & 1.13 & 2.6 & 4.0 & $\mathbf{0 . 1}$ & $\mathbf{1 . 6 5}$ \\
$\alpha-\mathrm{Al}_{2} \mathrm{O}_{3}$ & 9.4 & 6.6 & 12.2 & 0.99 & 3 & 4.8 & $\mathbf{0 . 4 5}$ & $\mathbf{2 . 3 5}$ \\
$\gamma-\mathrm{Al}_{2} \mathrm{O}_{3}$ & 8.6 & 5.6 & 11.5 & 0.99 & 3 & 4.8 & $\mathbf{0 . 4}$ & $\mathbf{2 . 1}$ \\
$\mathrm{Al}(\mathrm{OH})_{3}$ & 9.8 & 7 & 12.6 & 0.6 & 2.9 & 4.6 & $\mathbf{0 . 4}$ & $\mathbf{2 . 1}$ \\
\hline
\end{tabular}

In our recent paper (Piasecki 2006) we have proposed the method for parameter transfer from the 2-pK TLM to the 1-pK TLM. Instead of re-fit original experimental data we have tried to reproduce the results given by the 2-pK TLM with the parameter values published by Sverjensky (2005). To fit the output of both models we have used the trial and error method and visual control of results. In this case it is simple but very efficient method because we try to overlap two lines (e.g. two surface charge curves) instead of fitting theoretical curve to experimental data points. Using the computer program written by us we could calculate and visualize the proton surface charge, electrokinetic potential, and adsorption isotherms of electrolyte ions as $\mathrm{pH}$ functions.

The parameter values used in the calculations were collected in Tables 1-2. All the calculations were performed for the electrolyte concentration equal to $0.01 \mathrm{~mol} / \mathrm{dm}^{3}$. For different values of ionic strength (e.g. $0.1 \mathrm{~mol} / \mathrm{dm}^{3}$ or $0.001 \mathrm{~mol} / \mathrm{dm}^{3}$ ) we have obtained the similar fit quality. It was assumed that the inner-layer capacitance $c_{1}$ should have the same value for the both models, which is justified because the e.d.l. capacitance depends only on the type of oxide and electrolyte. Additionally, the outer-layer capacitance $c_{2}$ was assumed to be constant in the all calculations and the standard literature value was used $\left(c_{2}=0.2 \mathrm{~F} / \mathrm{m}^{2}\right)$.

The proton adsorption constants $\log K_{1}, \log K_{2}$, and $\log K_{+}$are related with PZC (point of zero charge, i.e. pH for which oxide surface charge is equal to zero):

$\mathrm{PZC}=\frac{1}{2}\left(\log K_{1}+\log K_{2}\right)$

$\mathrm{PZC}=\log K_{+}$

In our calculations we used the definition of the standard state for sorption sites and sorbate species proposed by Sverjensky to make the parameter values independent of the oxide sample properties (Sverjensky 2003). We used the standard state sorbate species site density $\mathrm{N}^{\text {st }}=10 \times$ $10^{18}$ sites $/ \mathrm{m}^{2}$ and the standard state BET surface area $\mathrm{A}^{\text {st }}=$ $10 \mathrm{~m}^{2} / \mathrm{g}$.

We limit the fitting degrees of freedom to only two parameters: $\log K_{1 \mathrm{C}}$ and $\log K_{1 \mathrm{~A}}$. These parameters describe the cation and anion adsorption strength on the negatively and positively charged surface sites, respectively.

In Fig. 2 the results of applied fitting procedure were shown. Because the performance of fitting procedure is similar in each case, we only illustrated it for the $\alpha-\mathrm{TiO}_{2} / \mathrm{RbBr}$ system. In fitting process we focused only on the surface charge density and the adsorption isotherms of electrolyte ions. We can see that the fit quality is very good in this case. The electrokinetic potential given by the 1-pK approach is generally higher than the one predicted by the $2-\mathrm{pK}$ model if we use the same value of outer-layer capacitance $c_{2}$. The value of $c_{2}$ affects significantly the electrokinetic potential, and can be used as the $\zeta$-potential adjustable parameter. The 
Fig. 2 Fitting of results given by the 2-pK TLM for $\alpha-\mathrm{TiO}_{2} / \mathrm{RbBr}$ system with the 1-pK TLM. (A) surface charge density, (C) electrolyte ions adsorption isotherms,

(B) electrokinetic potential given here as reference. Dashed lines were generated by using the 2-pK TLM. Solid lines are best-fit obtained by using the 1-pK TLM. The parameters values are given in Table 1

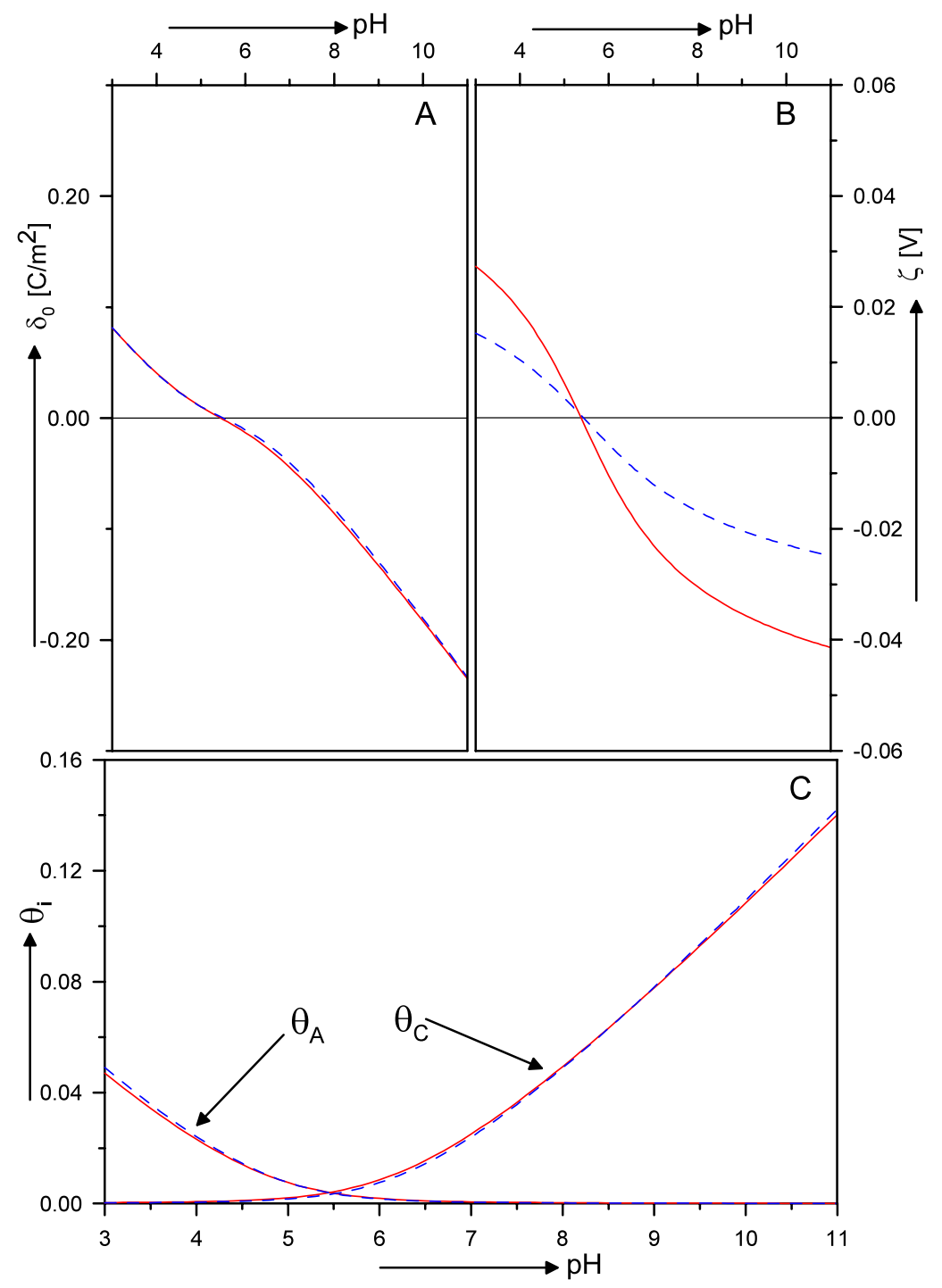

calculated surface charge and ion adsorption isotherms are practically insensitive to the changes in $c_{2}$.

In Tables 1 and 2 we present the parameter values used in our calculations for two salts $\mathrm{RbBr}$ and $\mathrm{NaF}$. The parameter values for $\mathrm{Na}^{+}$ion were taken from our previous paper (Piasecki 2006). In Table 3 we have collected the adsorption constant values for the all alkali metal cations and halide anions determined by using the 1-pK TLM. These data have also been shown in Figs. 3 and 4. In these Figures we can easy follow the adsorption affinities of ions for different oxides.

The adsorption constant values for alkali metal cations lie in the range from -0.5 to 1.5 . For each oxide the highest value of the adsorption constant was obtained for the lithium ion (its value changes from 0.0 to 1.5 ). For a given oxide the adsorption constants for $\mathrm{Na}^{+}, \mathrm{K}^{+}, \mathrm{Rb}^{+}, \mathrm{Cs}^{+}$are comparable (with a few exceptions like $\mathrm{K}^{+}$on $\alpha-\mathrm{TiO}_{2}$ ).
The adsorption constants for halide anions predicted by 1-pK TLM behave in different fashion. The values of anion adsorption constants lie in the range from -0.6 to 2.5 . The fluoride anion has the strongest adsorption affinity for each oxide among all considered anions. On the other hand the chloride ion exhibits the weakest affinity for each oxide among all considered anions. The iodine ion has higher adsorption affinity than $\mathrm{Br}^{-}$and $\mathrm{Cl}^{-}$ions. It is noteworthy that the affinity sequences for each oxide are parallel to each other.

In Figs. 5 and 6 we depicted the adsorption constants for alkali cations and halide anions determined by Sverjensky for the 2-pK TLM. It is obvious that the transition from 2-pK TLM to 1-pK TLM does not change adsorption sequence for given oxide. The both models are nonlinear so the relations between their parameters are not straightforward and can not be predicted a priori. 
Table 3 The values of adsorption constants of alkali metal cations and halide anions on different oxides determined by using 1-pK TLM in this study and in our previous paper (Piasecki 2006)

\begin{tabular}{|c|c|c|c|c|c|c|c|c|c|}
\hline \multirow[t]{2}{*}{ Oxide } & \multicolumn{5}{|c|}{$\log K_{1 \mathrm{C}}$} & \multicolumn{4}{|c|}{$\log K_{1 \mathrm{~A}}$} \\
\hline & $\overline{\mathrm{Li}^{+}}$ & $\mathrm{Na}^{+}$ & $\mathrm{K}^{+}$ & $\mathrm{Rb}^{+}$ & $\mathrm{Cs}^{+}$ & $\overline{\mathrm{F}^{-}}$ & $\mathrm{Cl}^{-}$ & $\mathrm{Br}^{-}$ & $\mathrm{I}^{-}$ \\
\hline $\mathrm{Fe}_{3} \mathrm{O}_{4}$ & 1.5 & 0.85 & 0.5 & 0.5 & 0.4 & 2.45 & 0.25 & 0.3 & 1.0 \\
\hline$\alpha-\mathrm{MnO}_{2}$ & 0.5 & -0.05 & -0.2 & -0.1 & -0.1 & 2.45 & -0.25 & 0.0 & 0.6 \\
\hline$\alpha-\mathrm{TiO}_{2}$ & 0.5 & -0.05 & -0.5 & -0.1 & -0.2 & 2.1 & -0.15 & 0.0 & 0.7 \\
\hline$\beta-\mathrm{TiO}_{2}$ & 0.0 & -0.3 & -0.45 & -0.2 & -0.3 & 1.4 & -0.6 & -0.4 & 0.35 \\
\hline $\mathrm{Fe}_{2} \mathrm{O}_{3}$ & 0.5 & 0.1 & 0.1 & 0.2 & 0.3 & 1.65 & -0.35 & -0.3 & 0.55 \\
\hline$\alpha-\mathrm{Al}_{2} \mathrm{O}_{3}$ & 1.05 & 0.45 & 0.45 & 0.4 & 0.4 & 2.35 & 0.15 & 0.3 & 1.1 \\
\hline$\gamma-\mathrm{Al}_{2} \mathrm{O}_{3}$ & 1.0 & 0.4 & 0.3 & 0.3 & 0.3 & 2.1 & -0.05 & 0.1 & 0.85 \\
\hline $\mathrm{Al}(\mathrm{OH})_{3}$ & 0.85 & 0.4 & 0.3 & 0.3 & 0.4 & 2.1 & -0.05 & 0.1 & 0.85 \\
\hline
\end{tabular}

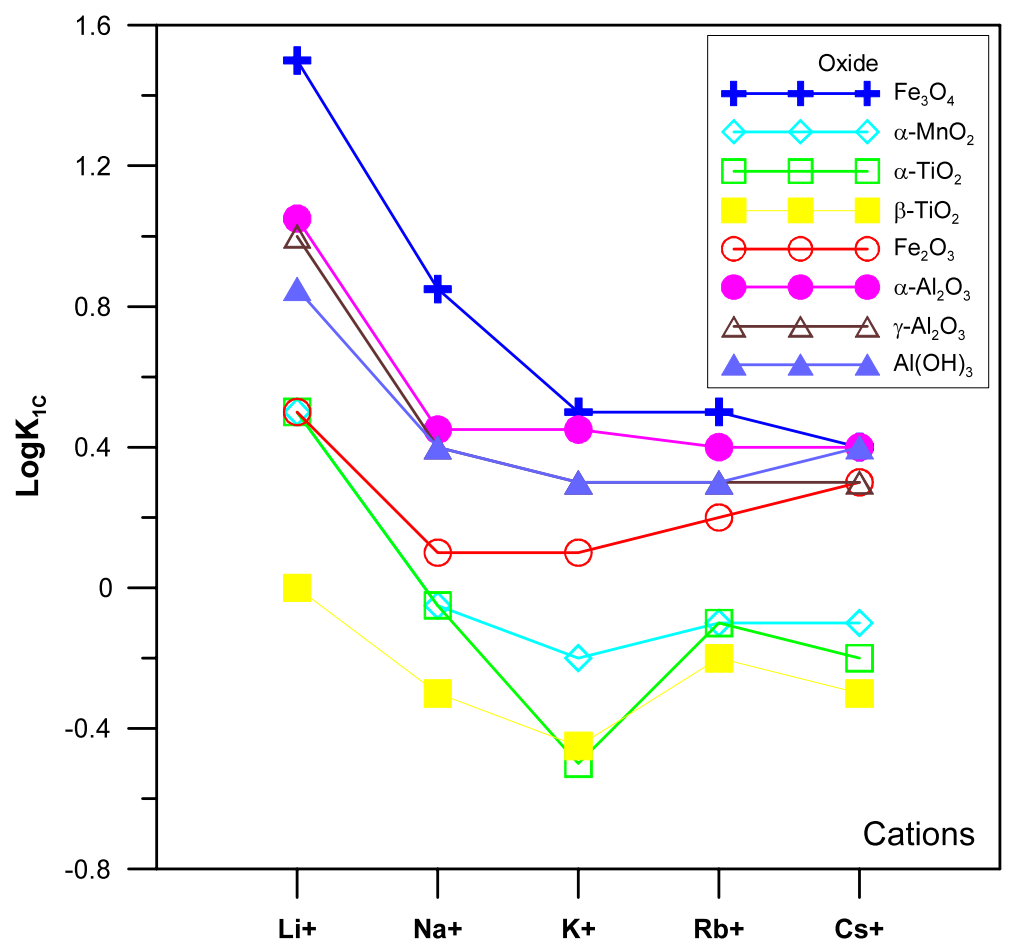

Fig. 3 Adsorption constants of alkali metals cations for different oxides determined by using the 1-pK TLM
According to Sverjensky the dielectric constant of solid is a key factor which determines the adsorption affinity of electrolyte ions (Sverjensky 2005). For oxides with high dielectric constant (like rutile), adsorption equilibrium constants of cations should increase in the sequence $\mathrm{Cs}^{+}<\mathrm{Rb}^{+}<$ $\mathrm{K}^{+}<\mathrm{Na}^{+}<\mathrm{Li}^{+}$(i.e. the affinity increases with decreasing crystallographic ion radius-this is so-called indirect Hofmeister series). For titanium oxides the same sequence was also obtained by Bourikas et al. (2001). In contrast, for oxides with low dielectric constant (like silica), adsorption affinity increases in the opposite direction $\mathrm{Li}^{+}<\mathrm{Na}^{+}<$ $\mathrm{K}^{+}<\mathrm{Rb}^{+}<\mathrm{Cs}^{+}$(this is direct Hofmeister series). For oxides with intermediated equilibrium constants (like aluminium and iron oxides) alkali metal cations should adsorb in similar extent.

Different approach was used by Rahnemaie et al. who traced the location of electrolyte ions on goethite/solution interface by using the CD-MUSIC (Charge Distribution Multi-Site Complexation Model) (Rahnemaie et al. 2006). They found that $\mathrm{Cl}^{-}$ions are relatively close to the surface, $\mathrm{Li}^{+}, \mathrm{Na}^{+}, \mathrm{NO}_{3}^{-}, \mathrm{ClO}_{4}^{-}$ions are located in the intermediate positions, and $\mathrm{K}^{+}, \mathrm{Rb}^{+}, \mathrm{Cs}^{+}$cations are farthest from the surface.

Johnson et al. (1999) who used an electroacoustic technique to study the binding of monovalent ions on $\alpha$-alumina obtained the following sequence for the cations: $\mathrm{Li}^{+}>$ $\mathrm{Na}^{+}>\mathrm{K}^{+} \approx \mathrm{Cs}^{+}$. They also found that the anions $\mathrm{Br}^{-}$, $\mathrm{Cl}^{-}, \mathrm{I}^{-}$, and $\mathrm{NO}_{3}^{-}$adsorb in very similar extend. From our results it follows that sodium, potassium and caesium have very similar affinities to $\alpha$-alumina, and $\mathrm{I}^{-}$ion has higher affinity than $\mathrm{Br}^{-}$and $\mathrm{Cl}^{-}$ions.

Sahai (2000) who analyzed adsorption enthalpies of electrolyte ions on oxide surfaces found that exothermicity of the cation adsorption enthalpies increased as 
Fig. 4 Adsorption constants of halide anions for different oxides determined by using the 1-pK TLM

Fig. 5 Adsorption constants of alkali metals cations for different oxides determined by Sverjensky for the 2-pK TLM (data from Table 6 in Sverjensky 2005)
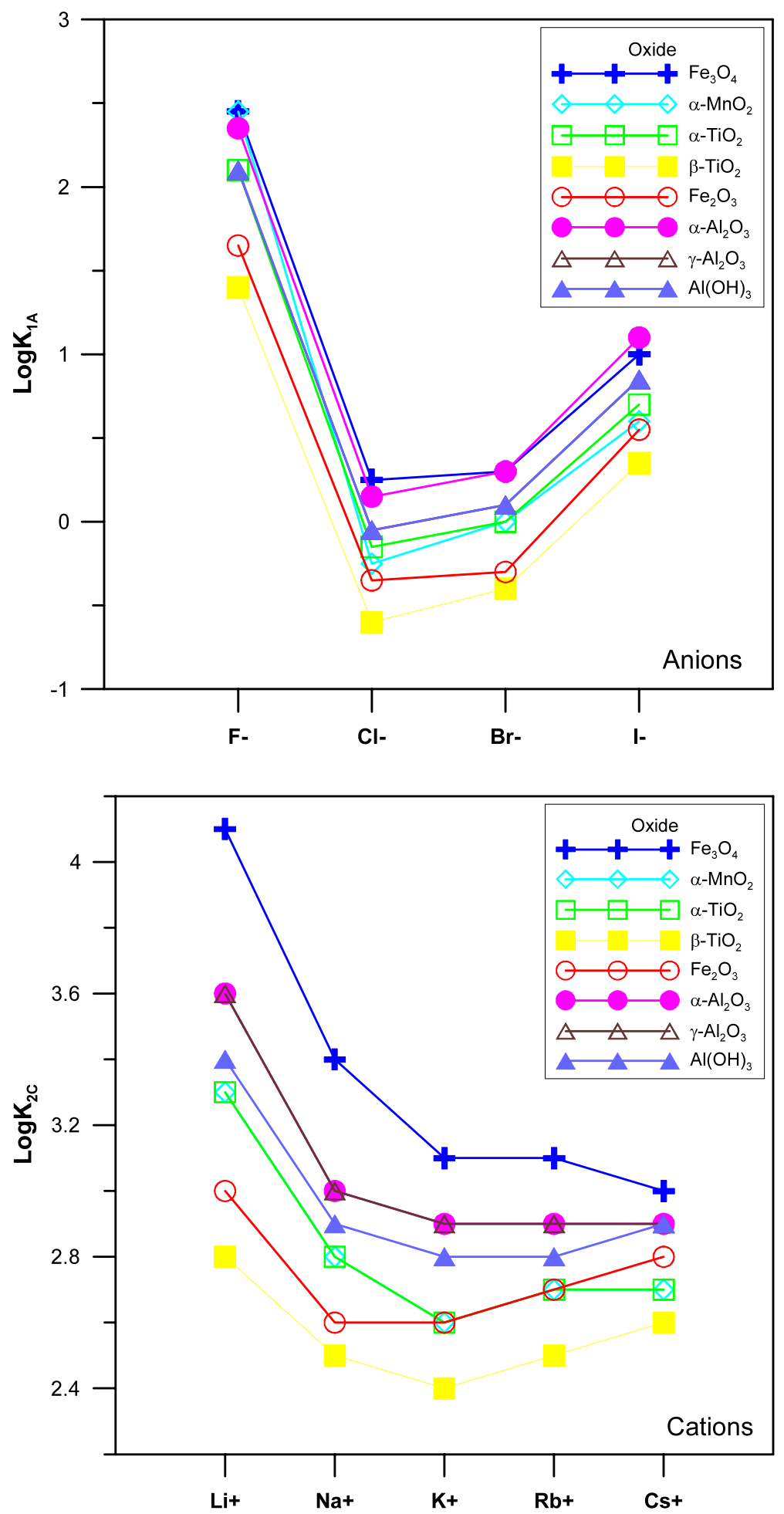

$\mathrm{Cs}^{+}<\mathrm{Rb}^{+}<\mathrm{K}^{+}<\mathrm{Na}^{+}<\mathrm{Li}^{+}$for all oxides except quartz and amorphous $\mathrm{SiO}_{2}$ where reversed trend was observed. For enthalpies of anion adsorption, exothermicity increased as $\mathrm{I}^{-}<\mathrm{Br}^{-}<\mathrm{Cl}^{-}<\mathrm{F}^{-}$for all oxides excluding again quartz and silica. However Sahai and Sverjensky analyses were based on the same theoretical background also other observations confirm their findings (Lyklema 2009).

Lyklema gave simple expalanation of Hofmeister series (Lyklema 2009). He wrote: "The evidence collected so far appears in line with the trend that small (unhydrated) ions prefer small (unhydrated) sites whereas big ions prefer big 
Fig. 6 Adsorption constants of halide anions for different oxides determined by Sverjensky for the 2-pK TLM (data from Table 7 in Sverjensky 2005)

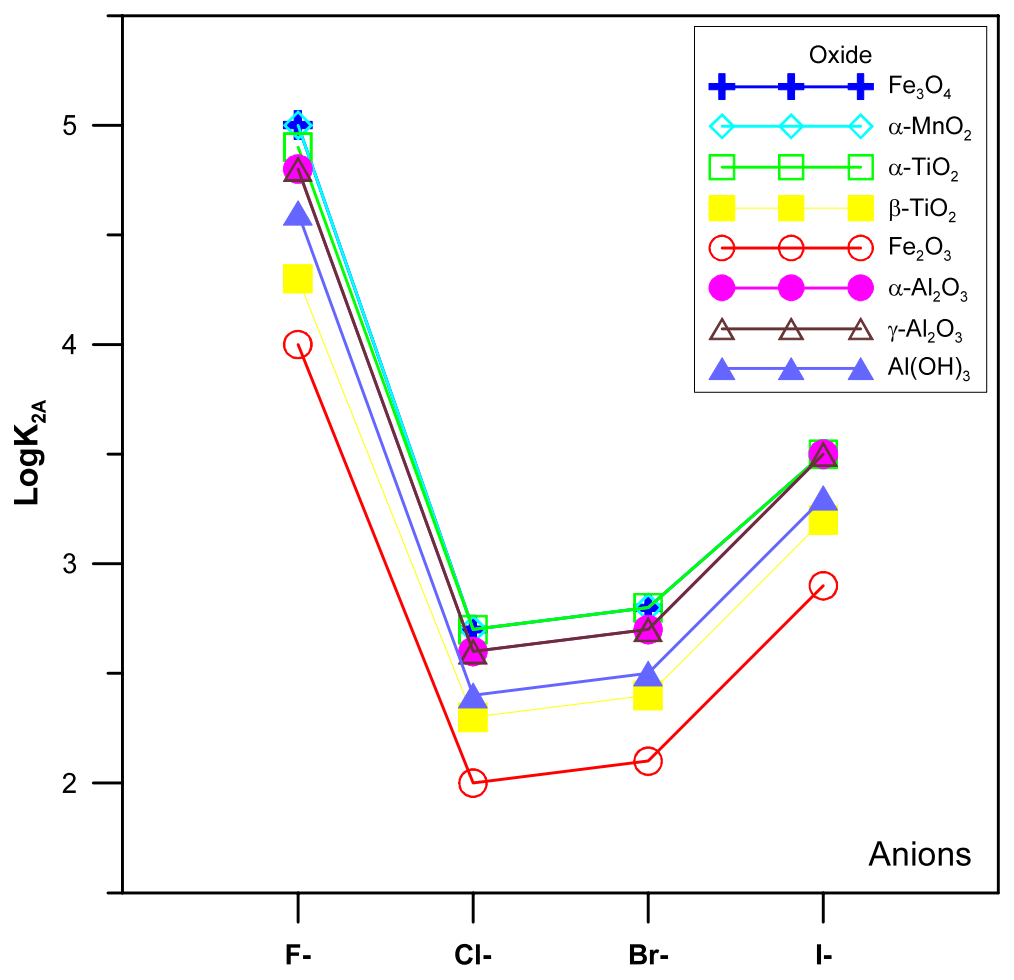

adsorption sites". He called the above rule "Like seeks Like". This is also know as the empirical law of matching water affinities (Collins et al. 2007) and was confirmed by ab initio calculations which showed that small cations prefer small charged headgroups (like carboxyl) and larger cations prefer larger headgroups (like methylsulfate) (Vlachy et al. 2009).

Recent experimental and theoretical studies indicate that the dominant forces acting on ions in water are short range chemical forces and long range electrical fields generated by ions in solution are weaker than water-water interactions (Collins et al. 2007). So the models of ion solvation based on macroscopic dielectric constant (e.g. Born model) overestimate the role of electrostatic interaction in electrolyte solution.

According to Zhang and Cremer the Hofmeister effect is a manifestation of the direct interactions of the ions and a macromolecule as well as interactions of ions and waters molecules from the first hydration shell of macromolecule (Zhang and Cremer 2006).

Kosmulski discovered the differentiating effect of small cations in the shift of the isoelectric point of oxides at high ionic strengths (Kosmulski 2002). At high concentration of electrolyte the importance of the ion-ion and ion-solvent interactions increases considerably, so in such conditions the electrolyte cations and anions cannot be treated independently what was assumed in our investigations (however our study was limited to rather low concentration of electrolyte).

Schwierz et al. (2010) investigated the role of surface polarity and surface charge on anionic Hofmeister series.
They used explicit-solvent MD simulations and PoissonBoltzmann theory of e.d.l. to calculate ionic distribution at surfaces of different polarity and charge. They obtained the direct anionic Hofmeister series for negatively charged hydrophobic surfaces and positive hydrophylic surfaces. The reversed Hofmeister series were obtained for positive nonpolar surfaces and negative polar surfaces.

Parsons et al. (2010) took into account nonelectrostatic ion-surface potential and hydration of ions to determine the Hofmeister series for alkali ions at alumina and silica surfaces. They obtained the direct series for silica and the indirect series for alumina.

It is obvious from the above discussion that the origin of Hofmeister series can not be fully explained by mechanistic models like the 1-pK TLM. Nevertheless, in this paper we have shown that two different surface complexation models predict the same sequence of monovalent ion affinities.

\section{Summary}

Based on the parameter values published by Sverjensky for the 2-pK TLM we have predicted the adsorption constants for three monovalent ions $\left(\mathrm{Rb}^{+}, \mathrm{F}^{-}, \mathrm{Br}^{-}\right)$by using the 1-pK TLM. Applying these predicted values along with the parameter values determined in our earlier paper we were able to compare the adsorption constants of alkali metal cations and halide anions. The order of ions in the Hofmeister series for alkali metal cations $\left(\mathrm{Cs}^{+} \approx \mathrm{Rb}^{+} \approx \mathrm{K}^{+}<\mathrm{Na}^{+}<\mathrm{Li}^{+}\right)$ 
is in agreement with the earlier findings, but the sequence for halide anions $\left(\mathrm{F}^{-} \gg \mathrm{Cl}^{-} \approx \mathrm{Br}^{-}<\mathrm{I}^{-}\right)$is intriguing and surprisingly reproduces for each analyzed oxide. The anion adsorption on oxides seems to be less understood than the cation adsorption.

Surface complexation models can not explain the origin of lyotropic series for metal oxides, however these series seem to be invariable when we change one model to another (at least for the 1-pK and 2-pK models). The differences in the mechanism of cation and anion adsorption on oxides will be studied using molecular dynamics simulations in our future work.

Open Access This article is distributed under the terms of the Creative Commons Attribution Noncommercial License which permits any noncommercial use, distribution, and reproduction in any medium, provided the original author(s) and source are credited.

\section{References}

Bourikas, K., Hiemstra, T., Riemsdijk, W.H.V.: Ion pair formation and primary charging behavior of titanium oxide (anatase and rutile). Langmuir 17, 749-756 (2001)

Collins, K.D., Neilson, G.W., Enderby, J.E.: Ions in water: Characterizing the forces that control chemical processes and biological structure. Biophys. Chem. 128, 95-104 (2007)

Davis, J.A., James, R.O., Leckie, J.O.: Surface ionization and complexation at the oxide/water interface I. Computation of electrical double layer properties in simple electrolytes. J. Colloid Interface Sci. 63, 480-499 (1978)

Davis, J.A., Kent, D.B.: Surface complexation modeling in aqueous geochemistry. In: Hochella, M.F. Jr., White, A.F. (eds.) MineralWater Interface Geochemistry, pp. 177-259. Mineralogical Society of America, Washington (1990)

Hiemstra, T., van Riemsdijk, W.H.: Physical chemical interpretation of primary charging behavior of metal (hydr)oxides. Colloids Surf. 59, 7-25 (1991)

Hiemstra, T., Venema, P., van Riemsdijk, W.H.: Intrinsic proton affinity of reactive surface groups of metal (Hydr)oxides: The bond valence principle. J. Colloid Interface Sci. 184, 680-692 (1996)

James, R.O., Healy, T.W.: Adsorption of hydrolyzable metal ions at the oxide-water interface III. A thermodynamic model of adsorption. J. Colloid Interface Sci. 40, 65-81 (1972)

Johnson, S.B., Scales, P.J., Healy, T.W.: The binding of monovalent electrolyte ions on $\alpha$-alumina. I. Electroacoustic studies at high electrolyte concentrations. Langmuir 15, 2836-2843 (1999)

Kosmulski, M.: Confirmation of the differentiating effect of small cations in the shift of the isoelectric point of oxides at high ionic strengths. Langmuir 18, 785-787 (2002)
Lyklema, J.: Simple Hofmeister series. Chem. Phys. Lett. 467, 217 222 (2009)

Parsons, D.F., Bostrom, M., Maceina, T.J., Salis, A., Ninham, B.W.: Why direct or reversed Hofmeister series? Interplay of hydration, non-electrostatic potentials, and ion size. Langmuir 26, 3323$3328(2010)$

Piasecki, W.: Determination of the parameters for the 1-pK triple-layer model of ion adsorption onto oxides from known parameter values for the 2-pK TLM. J. Colloid Interface Sci. 302, 389-395 (2006)

Rahnemaie, R., Hiemstra, T., Riemsdijk, W.H.V.: A new surface structural approach to ion adsorption: Tracing the location of electrolyte ions. J. Colloid Interface Sci. 293, 312-321 (2006)

Sahai, N.: Estimating adsorption enthalpies and affinity sequences of monovalent electrolyte ions on oxide surfaces in aqueous solution. Geochim. Cosmochim. Acta 64, 3629-3641 (2000)

Sahai, N.: Is silica really an anomalous oxide? Surface acidity and aqueous hydrolysis revisited. Environ. Sci. Technol. 36, 445-452 (2002)

Sahai, N., Sverjensky, D.A.: Evaluation of internally-consistent parameters for the triple-layer model by the systematic analysis of oxide surface titration data. Geochim. Cosmochim. Acta 61, 28012826 (1997a)

Sahai, N., Sverjensky, D.A.: Solvation and electrostatic model for specific electrolyte adsorption. Geochim. Cosmochim. Acta 61, 2827-2848 (1997b)

Schwierz, N., Horinek, D., Netz, R.R.: Reversed anionic Hofmeister series: the interplay of surface charge and surface polarity. Langmuir 26, 7370-7379 (2010)

Stumm, W., Morgan, J.J.: Aquatic Chemistry: Chemical Equilibria and Rates in Natural Waters. Wiley, New York (1996)

Sverjensky, D.A.: Zero-point-of-charge prediction from crystal chemistry and solvation theory. Geochim. Cosmochim. Acta 58, 31233129 (1994)

Sverjensky, D.A.: Standard states for the activities of mineral surfacesites and species. Geochim. Cosmochim. Acta 67, 17-28 (2003)

Sverjensky, D.A.: Prediction of surface charge on oxides in salt solutions: revisions for $1: 1\left(\mathrm{M}^{+} \mathrm{L}^{-}\right)$electrolytes. Geochim. Cosmochim. Acta 69, 225-257 (2005)

Sverjensky, D.A., Sahai, N.: Theoretical prediction of single-site surface protonation equilibrium constants for oxides and silicates in water. Geochim. Cosmochim. Acta 60, 3773-3798 (1996)

Vlachy, N., Jagoda-Cwiklik, B., Vacha, R., Touraud, D., Jungwirth, P., Kunz, W.: Hofmeister series and specific interactions of charged headgroups with aqueous ions. Adv. Colloid Interface Sci. 146, 42-47 (2009)

Yates, D.E., Levine, S., Healy, T.W.: Site-binding model of the electrical double layer at the oxide/water interface. J. Chem. Soc. Faraday Trans. 70, 1807-1818 (1974)

Yoon, R.H., Salman, T., Donnay, G.: Predicting points of zero charge of oxides and hydroxides. J. Colloid Interface Sci. 70, 483-493 (1979)

Zhang, Y., Cremer, P.S.: Interactions between macromolecules and ions: the Hofmeister series. Curr. Opin. Chem. Biol. 10, 658-663 (2006) 